\title{
Short communication: The mammalian lignan enterolactone is absorbed by newborn dairy calves fed enterolactone-enriched milk
}

\author{
C. P. Ghedini, ${ }^{*}$ N. L. Whitehouse, ${ }^{*}$ D. C. Moura, $†$ A. S. Oliveira, $†$ and A. F. Brito* \\ *Department of Agriculture, Nutrition, and Food Systems, University of New Hampshire, Durham 03824 \\ †Instituto de Ciências Agrárias e Ambientais, Universidade Federal de Mato Grosso-Campus Sinop, Sinop, MT, Brazil, 78557-267
}

\section{ABSTRACT}

Flaxseed is the richest source of the plant lignan secoisolariciresinol diglucoside, which is converted to the mammalian lignans enterolactone (EL) and enterodiol by the gut microbiota of ruminants and humans. Enterolactone has been associated with improved animal and human health due to its antioxidant and anticarcinogenic properties. The objective of this study was to determine the pharmacokinetics of EL in newborn dairy calves fed milk replacer or EL-enriched milk. We hypothesized that newborn Holstein calves fed ELenriched milk would have greater area under the curve and plasma concentration of EL compared with those fed milk replacer. On d 5 of life, calves were administered $2 \mathrm{~L}$ of milk replacer $(\mathrm{n}=10$; low-EL treatment: $123 \mathrm{nmol} / \mathrm{L}$ of EL) or $2 \mathrm{~L}$ of EL-enriched milk ( $\mathrm{n}=$ 10; high-EL treatment: $481 \mathrm{nmol} / \mathrm{L}$ of EL) during the morning feeding $(0700 \mathrm{~h})$. Blood samples were taken from the jugular vein before $(0 \mathrm{~h})$ and at $0.5,1,1.5,2$, $2.5,3,4,6,8,10,12,24$, and $48 \mathrm{~h}$ after oral administration of treatments. The area under the curve for the plasma concentration of EL was analyzed according to the trapezoidal rule between 0 and $12 \mathrm{~h}$ after treatment administration, and it was greater in high- $(26 \mathrm{nmol} / \mathrm{L}$ $\times \mathrm{h})$ than low-EL calves $(4.30 \mathrm{nmol} / \mathrm{L} \times \mathrm{h})$. Similarly, the maximum concentration of EL in plasma was greater in high- $(5.06 \mathrm{nmol} / \mathrm{L})$ versus low-EL calves $(1.95$ $\mathrm{nmol} / \mathrm{L})$. Furthermore, the time after treatment intake to reach maximum plasma concentration of EL was faster in high- $(4.31 \mathrm{~h})$ compared with low-EL $(4.44 \mathrm{~h})$ treatment. Calves were able to absorb EL, indicating that EL-enriched milk can potentially be used as source of EL to pre-weaned ruminants.

Key words: enterolactone, dairy calf, lignan, pharmacokinetics, secoisolariciresinol diglucoside

Received April 29, 2017.

Accepted June 17, 2017.

${ }^{1}$ Corresponding author: andre.brito@unh.edu

\section{Short Communication}

Lignans are polyphenolic, phytoestrogenic compounds known to elicit a wide range of biological effects, including weak estrogenic, antiestrogenic, antioxidant, anti-inflammatory, anticarcinogenic, and cardioprotective activities (Adolphe et al., 2010; Imran et al., 2015). Flaxseed (Linum usitatissimum L.) is the richest source of the lignan secoisolariciresinol diglucoside (SDG), which is a precursor for the synthesis of the mammalian lignans enterolactone (EL) and enterodiol (ED) by the gut microbiota of humans (Gaya et al., 2016) and ruminants (Gagnon et al., 2009). Feeding incremental amounts of flaxseed meal to dairy cows linearly increased the milk concentration of EL, but no ED was detected in milk (Petit et al., 2009). Therefore, ELenriched milk has the potential to be used as a source of EL for humans not only because milk is consumed by a large part of the world population, but also due to a poor and variable intake of plant lignans worldwide, including in the United States (de Kleijn et al., 2001).

Newborn calves often experience diarrhea, respiratory diseases, and oxidative stress, which contribute to high rates of morbidity and mortality during the first weeks of life (Inanami et al., 1999; Gaál et al., 2006; Uetake, 2013). In addition, poor colostrum quality is associated with low concentration of antioxidants (Maciej et al., 2015), suggesting that feeding EL-enriched milk to newborn and preweaned calves may be a viable strategy to mitigate oxidative stress. In newborn calves, suckling stimulates the reflex closure of the esophageal groove so that milk or milk replacer (MR) bypass the reticulo-rumen down to the abomasum. Thus, calves may be used as a model to make inferences about the pharmacokinetics of EL in simple-stomach mammals including humans. We hypothesized that compared with calves fed MR, those fed EL-enriched milk would have increased area under the curve (AUC), as well as greater maximum plasma concentration $\left(\mathbf{C}_{\max }\right)$ of EL and faster time to reach $\mathrm{C}_{\max }\left(\mathbf{T}_{\max }\right)$. The objective of this study was to determine the pharmacokinetics of EL from MR or EL-enriched milk consumed by newborn Holstein calves. 
This experiment was conducted at the University of New Hampshire Fairchild Dairy Teaching and Research Center (Durham, NH) from May to August 2015 and was approved by the University of New Hampshire Institutional Animal Care and Use Committee (protocol no. 15303). Twenty Holsteins calves $(\mathrm{n}=10$ males and 10 females) were used from birth to $\mathrm{d} 7$ of life. Calves were removed from dams immediately after birth and before nursing, weighed, navel-dipped with $7 \%$ iodine (vol:vol), and placed in individual pens $(1 \times 2.15 \mathrm{~m})$ located in an enclosed calf room. The 10 calves $(\mathrm{n}=$ 6 males and 4 females) born from multiparous cows received $4 \mathrm{~L}$ of colostrum using nipple bottles, with the first $2 \mathrm{~L}$ fed immediately after they were moved to the pens and the remaining $2 \mathrm{~L}$ within the first $24 \mathrm{~h}$ of life. The 10 calves $(\mathrm{n}=4$ males and 6 females) born from primiparous cows were fed $4 \mathrm{~L}$ of stored colostrum from multiparous cows when available or colostrum replacer (Ultra Start 150 Plus, Milk Products LLC, Chilton, WI) split in 2 daily allotments of $2 \mathrm{~L}$ each as done for calves born from multiparous cows. When colostrum or colostrum replacer was completely refused or not fully consumed voluntarily within approximately $15 \mathrm{~min}$ after offering the meal, refusal was administered via an esophageal tube to ensure uniform consumption among animals. Calves had free access to water and no access to starter grain while enrolled in the study.

From d 2 to 4 of life, nipple bottles were used to feed $4 \mathrm{~L} / \mathrm{d}$ of nonmedicated MR (Calf Care All-Milk 22-20, Poulin Grain, Newport, VT) to all calves in 2 daily allotments (0700 and $1900 \mathrm{~h}$ ) by mixing $300 \mathrm{~g}$ of MR powder plus $2 \mathrm{~L}$ of warm tap water following standard operation procedures of our dairy facility. On d 5 of life, calves were randomly assigned to 1 of 2 treatments: low milk EL (L-EL; $\mathrm{n}=5$ females and 5 males) or high milk EL (H-EL; $\mathrm{n}=5$ females and 5 males). Calves assigned to the H-EL treatment had MR substituted for $2 \mathrm{~L}$ of EL-enriched milk during the morning feeding on d 5 of life, whereas L-EL calves continued to receive $2 \mathrm{~L}$ of MR per feeding until d 7. Administration of MR resumed at $1900 \mathrm{~h}$ on d 5 for H-EL calves and continued through d 7 . All calves completely consumed the MR or EL-enriched milk within 5 min after the meal was offered. The EL-enriched milk used in the current study was collected over 3 consecutive afternoon milkings (total $=28 \mathrm{~kg}$ ) from 1 multiparous Jersey cow fed a TMR containing (DM basis) $15 \%$ flaxseed meal and $12 \%$ liquid molasses (Ghedini et al., 2016). Milk was stored at $-20^{\circ} \mathrm{C}$ in 3 -L plastic bottles for at least $90 \mathrm{~d}$ before being administered to the calves using nipple bottles. The concentration of EL (mean \pm SD) averaged $123 \pm 6.53 \mathrm{nmol} / \mathrm{L}$ and $481 \pm 65 \mathrm{nmol} / \mathrm{L}$ for MR and EL-enriched milk, respectively. The health status of all calves was evaluated daily while they were enrolled in the study (i.e., $7 \mathrm{~d}$ ) by monitoring signs of illness including lethargy, weakness, decreased appetite, fever, abnormal fecal consistency, cough, ocular or nasal discharge, and drooping ears using a calf health scoring chart (https://www.vetmed.wisc.edu/dms/ fapm/fapmtools/8calf/calf_health_scoring_chart.pdf; accessed Mar. 25, 2017).

Blood samples were taken from the jugular vein on $\mathrm{d} 5$ of life before $(0 \mathrm{~h})$ and at $0.5,1,1.5,2,2.5,3,4$, $6,8,10,12,24$, and $48 \mathrm{~h}$ after oral administration of MR or EL-enriched milk using 10-mL Vacutainer tubes containing $\mathrm{K}_{3}$-EDTA (Covidien, Minneapolis, MN). After collection, tubes were immediately transported to the laboratory and centrifuged $(3,300 \times \mathrm{g})$ for 20 min at $4^{\circ} \mathrm{C}$. Aliquots $(1.8 \mu \mathrm{L})$ of plasma were stored at $-80^{\circ} \mathrm{C}$ until EL analysis. Samples $(40 \mathrm{~mL})$ of MR and EL-enriched milk were taken during the morning feeding on $\mathrm{d} 5$ and stored at $-20^{\circ} \mathrm{C}$ for later EL analysis. Enterolactone in plasma, MR, and EL-enriched milk was extracted and hydrolyzed [ $\beta$-glucuronidase/ arylsulfatase from Helix pomatia (Roche-Diagnostics, Laval, QC, Canada)] according to procedures described previously (Gagnon et al., 2009). Enterolactone was analyzed colorimetrically (UV/visible spectrophotometer set at a wavelength of $405 \mathrm{~nm}$ ) in quadruplicates using a competitive enzymatic immunoassay (assay kit no. 500520, Cayman Chemical Co., Ann Arbor, MI) that recognizes both enantiomeric forms of EL. Plasma EL values were corrected by baseline concentrations of EL (i.e., 0-h blood sampling).

The AUC between 0 and $12 \mathrm{~h}\left(\mathrm{AUC}_{0-12 \mathrm{~h}}\right)$ after oral administration of MR or EL-enriched milk on d 5 of life was determined according to the trapezoidal rule (Phillips and Taylor, 1973). Both $\mathrm{C}_{\max (0-12 \mathrm{~h})}$ and $\mathrm{T}_{\max (0-12 \mathrm{~h})}$ were determined from individual baseline corrected plasma concentration time curves (Maciej et al., 2015). The apparent efficiency of absorption (AEA) of EL between 0 and $12 \mathrm{~h}$ was calculated assuming no change in plasma volume from d 1 to 5 of life using the following equation (Quigley et al., 1998):

$$
\begin{gathered}
\operatorname{AEA}_{0-12 \mathrm{~h}}(\%)=[\text { plasma EL }(\mathrm{mg} / \mathrm{L}) \times \mathrm{BW}(\mathrm{kg}) \\
\times 0.092 \div \text { EL intake }(\mathrm{mg})] \times 100
\end{gathered}
$$

The experiment was analyzed as a randomized complete block design with repeated measures over time [i.e., $\mathrm{AUC}_{0-12 \mathrm{~h}}, \mathrm{C}_{\max (0-12 \mathrm{~h})}$, and $\mathrm{T}_{\max (0-12 \mathrm{~h})}$ ] using the MIXED procedure of SAS (version 9.4, SAS Institute Inc., Cary, NC). Calves were blocked by date of birth yielding a total of 10 blocks with 2 animals/block. The random effect of block, as well as the fixed effects of treatment, time of blood sampling, and covariate measurements (i.e., initial BW and 0-h plasma concentra- 
tion of EL) were included in the statistical model. The random effect of calf within treatment was used as the error term. The covariate structure heterogeneous firstorder autoregressive yielded the lowest Bayesian information criterion and was retained in the final model. Body weight at birth, EL intake, plasma concentrations of $\operatorname{EL}(0,12,24$, and $48 \mathrm{~h})$, and $\mathrm{AEA}_{0-12 \mathrm{~h}}$ were analyzed without the repeated statement in the model. Data are reported as least squares means and standard error of the mean. Significance was declared at $P \leq 0.05$ and trends at $0.05<P \leq 0.10$.

All calves were born spontaneously without signs of illnesses. The concentration of EL averaged $123 \mathrm{nmol} / \mathrm{L}$ in MR and was about 80 and $26 \%$ greater than the EL content found in whole milk of Holstein (Petit and Gagnon, 2009; Petit et al., 2009) and Jersey (Brito et al., 2015) cows not supplemented with flaxseed meal, thus indicating that EL is more concentrated in MR than whole milk. Other non-SDG plant lignans such as matairesinol, pinoresinol, and lariciresinol have been shown to be converted to EL (Heinonen et al., 2001). Furthermore, the mean duodenal flow and fecal excretion of secoisolariciresinol, matairesinol, ED, and EL were greater than the intake of these metabolites, implying that plant lignans besides matairesinol and secoisolariciresinol are precursors of EL production in the rumen (Njåstad et al., 2014).

Initial BW and EL pharmokinetics results are presented in Table 1. Body weight at birth did not differ $(P=0.81)$ between treatments. As expected, EL intake was $314 \%$ greater $(P<0.001)$ in $\mathrm{H}$-EL than
L-EL calves. The $\mathrm{AUC}_{0-12 \mathrm{~h}}$ for plasma EL was greater $(P<0.001)$ in calves fed H-EL compared with those fed L-EL and averaged 26.0 and $4.30 \mathrm{nmol} / \mathrm{L} \times \mathrm{h}$, respectively. Similarly, $\mathrm{C}_{\max }(0-12 \mathrm{~h})$ was greater $(P<$ $0.001)$ in $\mathrm{H}-\mathrm{EL}(5.06 \mathrm{nmol} / \mathrm{L})$ versus L-EL calves $(1.95$ $\mathrm{nmol} / \mathrm{L})$. In addition, $\mathrm{T}_{\max }(0-12 \mathrm{~h})$ was reached $13 \mathrm{~min}$ faster $(P<0.001)$ in calves administered H-EL (4.31 h) than L-EL $(4.44 \mathrm{~h})$. Plasma concentrations of EL were greater at $12 \mathrm{~h}(3.21$ vs. $1.16 \mathrm{nmol} / \mathrm{L} ; P<0.001)$, $24 \mathrm{~h}(2.67$ vs. $1.07 \mathrm{nmol} / \mathrm{L} ; P<0.001)$, and $48 \mathrm{~h}(2.05$ vs. $1.07 \mathrm{nmol} / \mathrm{L} ; P<0.001)$ when feeding H-EL versus L-EL, respectively. However, no significant difference between treatments was observed for the baseline concentration (i.e., 0-h blood sampling) of EL in plasma. These results collectively suggest that EL was absorbed in the intestines of newborn dairy calves consuming MR or EL-enriched milk. As newborn calves experience high rates of oxidative stress, morbidity, and mortality (Inanami et al., 1999; Gaál et al., 2006; Uetake, 2013), administration of EL-enriched milk may be used as a feeding strategy with potential to improve calf health during the first weeks of life.

The plasma concentration of EL in calves assigned to L-EL returned to baseline $12 \mathrm{~h}$ after oral administration of MR, but not in calves administered H-EL (Figure 1). Maciej et al. (2015) reported that the plasma concentration of total flavonols, which are polyphenols with potential health-promoting properties, did not return to baseline $12 \mathrm{~h}$ after oral administration of quercetin aglycone or rutin to 2-d-old German Holstein calves. However, the plasma concentration of total flavonols

Table 1. Least squares means for BW at birth, and intake and pharmacokinetics of enterolactone (EL) in newborn Holstein calves fed milk replacer (low-EL; $\mathrm{n}=10$ ) or EL-enriched milk (high-EL; $\mathrm{n}=10$ )

\begin{tabular}{|c|c|c|c|c|}
\hline \multirow[b]{2}{*}{ Item $^{1}$} & \multicolumn{2}{|c|}{ Treatment } & \multirow[b]{2}{*}{ SEM } & \multirow[b]{2}{*}{$P$-value ${ }^{2}$} \\
\hline & Low-EL & High-EL & & \\
\hline $\mathrm{BW}, \mathrm{kg}$ & 41.3 & 42.2 & 2.39 & 0.81 \\
\hline EL intake, $\mu \mathrm{g}$ & 70.0 & 290 & 8.00 & $<0.001$ \\
\hline Plasma $\mathrm{AUC}_{0-12 \mathrm{~h}},{ }^{3} \mathrm{nmol} / \mathrm{L} \times \mathrm{h}$ & 4.30 & 26.0 & 1.69 & $<0.001$ \\
\hline Plasma $\mathrm{C}_{\max (0-12 \mathrm{~h})},{ }^{4} \mathrm{nmol} / \mathrm{L}$ & 1.95 & 5.06 & 0.30 & $<0.001$ \\
\hline Plasma $T_{\max (0-12 \mathrm{~h})},{ }^{2} \mathrm{~h}$ & 4.44 & 4.31 & 0.88 & $<0.001$ \\
\hline 0 -h plasma EL, nmol/L & 1.10 & 1.42 & 0.18 & 0.22 \\
\hline 12-h plasma EL, nmol/L & 1.16 & 3.21 & 0.30 & $<0.001$ \\
\hline 24-h plasma EL, nmol/L & 1.07 & 2.67 & 0.19 & $<0.001$ \\
\hline 48-h plasma EL, nmol/L & 1.07 & 2.05 & 0.28 & $<0.001$ \\
\hline $\mathrm{AEA}_{0-12 \mathrm{~h}},{ }^{6} \%$ & 1.85 & 1.31 & 0.20 & 0.08 \\
\hline
\end{tabular}

${ }^{1}$ Plasma EL data reported in this table were obtained from d 5 to 7 of life.

${ }^{2}$ Significance was declared at $P \leq 0.05$ and trends at $0.05<P \leq 0.10$.

${ }^{3}$ Area under the curve between 0 and $12 \mathrm{~h}\left(\mathrm{AUC}_{0-12 \mathrm{~h}}\right)$ on $\mathrm{d} 5$ of file was calculated by subtracting baseline values (0-h plasma EL) from all remaining time points according to the trapezoidal rule (Phillips and Taylor, 1973).

${ }^{4}$ Maximum plasma concentration of EL between 0 and $12 \mathrm{~h}\left[\mathrm{C}_{\max (0-12 \mathrm{~h})}\right]$ on $\mathrm{d} 5$ of life.

${ }^{5}$ Time to reach $\mathrm{C}_{\max }$ between 0 and $12 \mathrm{~h}\left[\mathrm{~T}_{\max (0-12 \mathrm{~h})}\right]$ on $\mathrm{d} 5$ of life.

${ }^{6}$ Apparent efficiency of absorption between 0 and $12 \mathrm{~h}\left(\mathrm{AEA}_{0-12 \mathrm{~h}}\right) ; \mathrm{AEA}_{0-12 \mathrm{~h}}(\%)=[$ plasma EL $(\mathrm{mg} / \mathrm{L}) \times \mathrm{BW}$

$(\mathrm{kg}) \times 0.092 \div \mathrm{EL}$ intake $(\mathrm{mg})] \times 100$ (Quigley et al., 1998). 


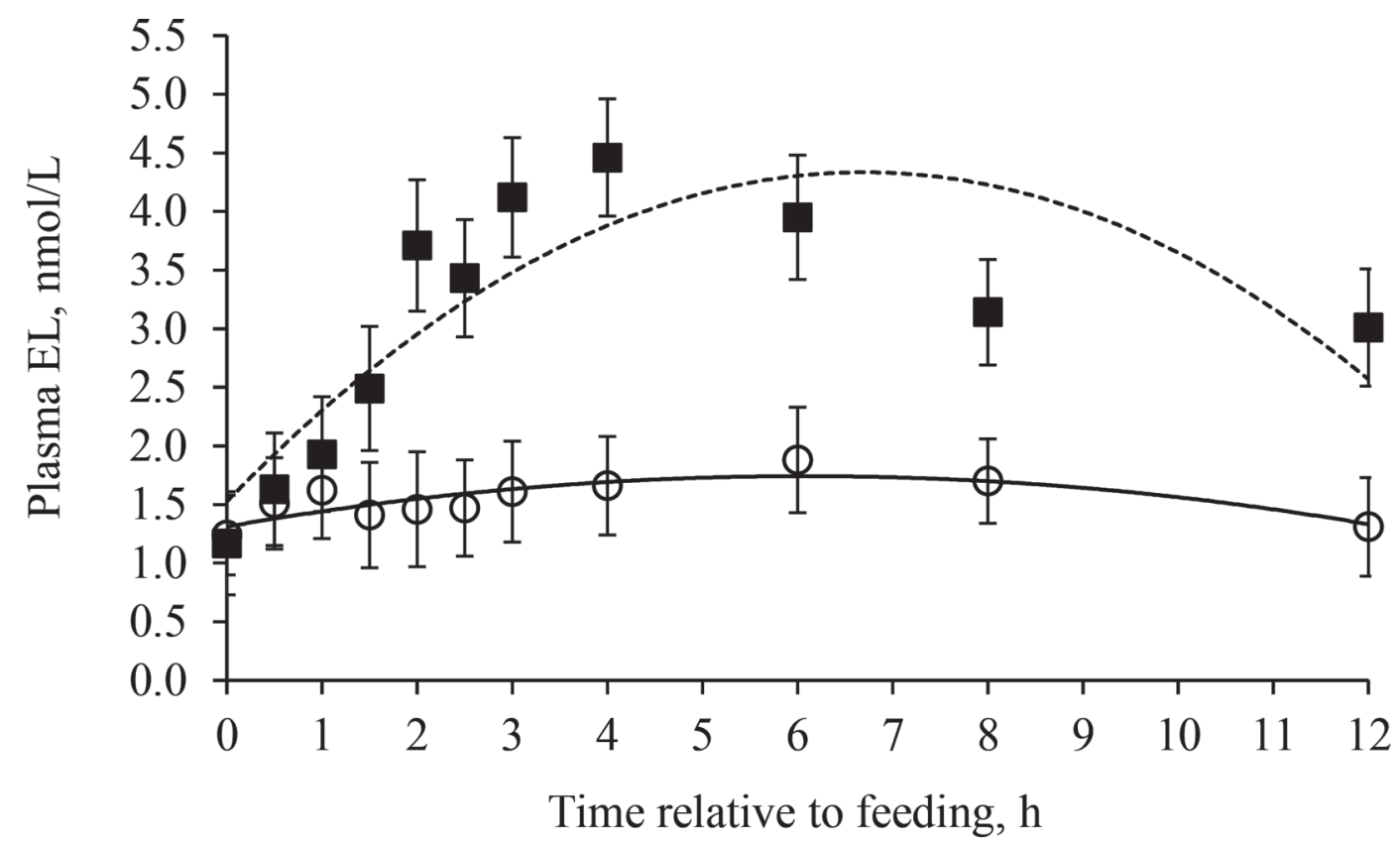

Figure 1. Plasma concentration time curve of enterolactone (EL) after oral administration of $2 \mathrm{~L}$ of milk replacer (low-EL treatment; $\bigcirc)$ or $2 \mathrm{~L}$ of EL-enriched milk (high-EL treatment; $\mathbf{0})$ to newborn calves on d 5 of life. Values are means \pm SD.

returned to baseline $48 \mathrm{~h}$ past oral dose (Maciej et al., 2015), whereas that of EL from EL-enriched milk did not (Figure 1). Whereas quercetin aglycone or rutin was fed as a single dose (Maciej et al., 2015), the oral administration of MR to H-EL calves resumed at 1900 $\mathrm{h}$ on $\mathrm{d} 5$ of life. This likely influenced the plasma concentration of EL at $48 \mathrm{~h}$ (d 7 of life) because the concentration of EL in MR averaged $123 \mathrm{nmol} / \mathrm{L}$.

It has been shown in vitro using human colon epithelial cells (Jansen et al., 2005) or rat and human intestinal and liver microsomes (Lin et al., 2013) that EL and ED are conjugated as glucuronides and sulfates. Conjugated EL and ED undergo extensive first-pass metabolism and enterohepatic recirculation (Jansen et al., 2005; Lin et al., 2013), as well as deconjugation by bacterial $\beta$-glucuronidases and sulfatases followed by reabsorption (Setchell and Adlercreutz 1988). In lactating dairy cows, absorption of EL and ED appears to occur in the rumen (Gagnon et al., 2009) and intestines (Njåstad et al., 2014), likely as conjugated forms. Therefore, it is conceivable that most EL found in ruminants' milk is conjugated with glucuronides and sulfates.

In the present study, newborn calves were able to absorb EL, indicating that they may have active $\beta$-glucuronidases produced by the intestinal microbiota or that absorption of EL was independent of enzymatic action. The activity of $\beta$-glucuronidase in humans has been attributed to intestinal-dominant bacteria belong- ing to Bacteroides, Bifidobacterium, Eubacterium, and Ruminococcus genera (Hawksworth et al., 1971; Akao, 2000). In ruminants, the presence of Bacteroides in the cecum and feces of Jersey calves has been reported as early as d 2 of life (Smith, 1965). Increased small intestinal tissue-attached Bifidobacterium $6 \mathrm{~h}$ after birth was reported in Holstein calves fed heat-treated colostrum (Malmuthuge et al., 2015). Bifidobacterium increased in fecal samples of calves between $\mathrm{d} 3$ and 7 of life, and active fecal $\beta$-glucuronidase was detected in all Bifidobacterium-positive calves (Rada et al., 2006). However, studies conducted with lactating dairy cows suggest marginal involvement of $\beta$-glucuronidase in the absorption of EL (Gagnon et al., 2009; De Marchi et al., 2016).

The $\mathrm{AEA}_{0-12 \mathrm{~h}}$ of EL was $<2 \%$ and tended $(P=0.08)$ to be lower in H-EL (1.31\%) than L-EL calves $(1.85 \%)$ as shown in Table 1. Interestingly, the oral bioavailability of ED averaged $<1 \%$ in Wistar rats (Mukker et al., 2015). Low bioavailability of enterolignans may be attributed to poor intestinal permeability or high first-pass metabolism and systemic clearance (Mukker et al., 2015). Guglielmini et al. (2012), reported an association between serum EL concentration $\geq 10$ nmol/L and decreased mortality risk (all-causes and breast cancer-specific) in women after breast cancer surgery. Milk concentration of EL averaged $395 \mathrm{nmol} / \mathrm{L}$ across 2 studies where Jersey cows received $15 \%$ of the diet DM as flaxseed meal (Brito et al., 2015; Ghedini 
et al., 2016). Thus, 1 daily serving $(250 \mathrm{~mL})$ of ELenriched milk with a concentration of $395 \mathrm{nmol} / \mathrm{L}$ of EL would result in $1.3 \mathrm{nmol} / \mathrm{L}$ of EL in plasma assuming an $\mathrm{AEA}_{0-12 \mathrm{~h}}$ of $1.31 \%$ (Table 1 ). This implies that EL-enriched milk needs to be consumed in combination with other lignan-rich foods to reach EL concentration in blood that has been linked to decreased mortality and cancer risks (Guglielmini et al., 2012). However, our inferences should be interpreted cautiously because calves in the present study were fed a liquid diet, which may have increased the passage rate of milk through the gastrointestinal tract, ultimately limiting EL absorption. Furthermore, the developing intestinal microbiota of newborn calves is likely unfit to fully metabolize conjugated EL. Thus, it is possible that the gut microbiota of adult humans would be able to metabolize EL-enriched milk more efficiently than that of newborn dairy calves.

Our hypothesis that the plasma AUC of EL would be greater in calves fed EL-enriched milk (H-EL treatment) compared with those fed MR (L-EL treatment) was confirmed, indicating that EL-enriched milk can be potentially used as a source of EL to pre-weaned calves. Further research is needed to better understand the absorption and transportation mechanisms of EL along the intestinal tract of newborn calves in the context of a developing gut microbiota. Dose-response studies, as well as factorial experiments feeding whole milk or MR supplemented or not with SDG should be also conducted in the future. Based on the pharmacokinetics data of EL derived from newborn dairy calves, humans should consume EL-enriched milk in combination with other lignan-rich foods to capitalize on potential health benefits. However, human-specific studies should be conducted due to the limitations of using newborn calves as a translational model for humans.

\section{ACKNOWLEDGMENTS}

This study was supported by the New Hampshire Agricultural Experiment Station and the USDA National Institute of Food and Agriculture (Hatch Multistate NC-1042 Project Number NH00616-R; Project Accession Number 1001855; New Hampshire Agricultural Experiment Station Scientific Contribution Number 2739). First author C. P. Ghedini and co-author D. C. Moura were funded by scholarships from CAPES (Brasília, DF, Brazil) and CNPq (Brasília, DF, Brazil), respectively. The authors thank the former graduate students André B. D. Pereira (University of New Hampshire; current affiliation: Purina Animal Nutrition LLC, Shoreview, MN) and Igor Alexandre de Souza (Universidade Estadual do Sudoeste da Bahia, Itapetinga, BA, Brazil; current affiliation: Universidade
Federal dos Vales do Jequitinhonha and Mucuri, Unaí, MG, Brazil) for support during blood sample collection. The scientific support and technical advice from Hélène V. Petit (Agri-Food and Agriculture Canada; Dairy and Swine Research and Development Centre, Sherbrooke, QC, Canada) is greatly appreciated. We finally thank the University of New Hampshire Fairchild Dairy Teaching and Research Center manager Jon Whitehouse and his staff for excellent animal care and overall research support.

\section{REFERENCES}

Adolphe, J. L., S. J. Whiting, B. H. J. Juurlink, L. U. Thorpe, and J. Alcorn. 2010. Health effects with consumption of the flax lignan secoisolariciresinol diglucoside. Br. J. Nutr. 103:929-938.

Akao, T. 2000. Competition in the metabolism of glycyrrhizin with glycyrrhetic acid mono-glucuronide by mixed Eubacterium sp. GLH and Ruminococcus sp. PO1-3. Biol. Pharm. Bull. 23:149-154.

Brito, A. F., H. V. Petit, A. B. D. Pereira, K. J. Soder, and S. Ross. 2015. Interactions of corn meal or molasses with a soybean-sunflower meal mix or flaxseed meal on production, milk fatty acid composition, and nutrient utilization in dairy cows fed grass haybased diets. J. Dairy Sci. 98:443-457.

de Kleijn, M. J. J., Y. T. van der Schouw, P. W. F. Wilson, H. Adlercreutz, W. Mazur, D. E. Grobbee, and P. F. Jacques. 2001. Intake of dietary phytoestrogens is low in postmenopausal women in the United States: The Framingham study. J. Nutr. 131:1826-1832.

De Marchi, F. E., M. F. Palin, G. T. Santos, C. Benchaar, and H. V. Petit. 2016. Effects of duodenal infusion of sunflower oil on $\beta$-glucuronidase activity and enterolactone concentration in dairy cows fed flax meal. Anim. Feed Sci. Technol. 220:143-150.

Gaál, T., R. Ribiczeyne-Szabo, K. Stadler, J. Jakus, J. Reiczigel, P. Kover, M. Mezes, and L. Sumeghy. 2006. Free radicals, lipid peroxidation and antioxidant system in the blood of cows and newborn calves around calving. Comp. Biochem. Physiol. B Biochem. Mol. Biol. 143:391-396.

Gagnon, N., C. Côrtes, D. da Silva, R. Kazama, C. Benchaar, G. dos Santos, L. Zeoula, and H. V. Petit. 2009. Ruminal metabolism of flaxseed (Linum usitatissimum) lignans to the mammalian lignan enterolactone and its concentration in ruminal fluid, plasma, urine and milk of dairy cows. Br. J. Nutr. 102:1015-1023.

Gaya, P., M. Medina, A. Sánchez-Jiménez, and J. M. Landete. 2016. Phytoestrogen metabolism by adult human gut microbiota. Molecules 21:1034-1050.

Ghedini, C. P., A. F. Brito, S. F. Reis, D. C. Moura, A. S. Oliveira, R. A. V. Santana, and A. B. D. Pereira. 2016. Liquid molasses decreases production linearly and changes enterolactone concentrations as a corn meal substitute in organic dairy cows fed flaxseed meal. Pages 1-8 in Organic Agriculture Research Symposium Proc., Pacific Grove, CA. http://eorganic.info/sites/eorganic .info/files/u27/4.6-Ghedini\&al-2016-Replacing_Corn_Meal-OARS _Proceedings-Final.pdf.

Guglielmini, P., A. Rubagotti, and F. Boccardo. 2012. Serum enterolactone levels and mortality outcome in women with early breast cancer: A retrospective cohort study. Breast Cancer Res. Treat. 132:661-668.

Hawksworth,, G., B. S. Draser, and M. J. Hill. 1971. Intestinal bacteria and the hydrolysis of glycosidic bonds. J. Med. Microbiol. 4:451-459.

Heinonen, S., T. Nurmi, K. Kiukkonen, K. Poutanen, K. Wähälä, T. Deyama, S. Nishibe, and H. Adlercreutz. 2001. In vitro metabolism of plant lignans: New precursors of mammalian lignans enterolactone and enterodiol. J. Agric. Food Chem. 49:3178-3186.

Imran, M., N. Ahmad, F. M. Anjum, M. K. Khan, Z. Mushtaq, M. Nadeem, and S. Hussain. 2015. Potential protective properties of flax lignan secoisolariciresinol diglucoside. Nutr. J. 14:71-77. 
Inanami, O., A. Shiga, K. J. Okada, R. Sato, Y. Miyake, and M. Kuwabara. 1999. Lipid peroxides and antioxidants in serum of neonatal calves. Am. J. Vet. Res. 60:452-457.

Jansen, G. H. E., I. C. M. Arts, N. W. F. Nielen, M. Muller, P. C. H. Hollman, and J. Keijer. 2005. Uptake and metabolism of enterolactone and enterodiol by human colon epithelial cells. Arch. Biochem. Biophys. 435:74-82.

Lin, C., E. S. Krol, and J. Alcorn. 2013. The comparison of rat and human intestinal and hepatic glucuronidation of enterolactone derived from flaxseed lignans. Nat. Prod. J. 3:159-171.

Maciej, J., T. Schäff, E. Kanitz, A. Tuchscherer, R. M. Bruckmaier, S. Wolffram, and H. M. Hammon. 2015. Bioavailability of the flavonol quercetin in neonatal calves after oral administration of quercetin aglycone or rutin. J. Dairy Sci. 98:3906-3917.

Malmuthuge, N., Y. Chen, G. Liang, L. A. Goonewardane, and L. L. Guan. 2015. Heat-treated colostrum feeding promotes beneficial bacteria colonization in the small intestine of neonatal calves. J. Dairy Sci. 98:8044-8053.

Mukker, J. K., R. S. P. Singh, A. D. Muir, E. S. Krol, and J. Alcorn. 2015. Comparative pharmacokinetics of purified flaxseed and associated mammalian lignans in male Wistar rats. Br. J. Nutr. 113:749-757.

Njåstad, K. M., S. A. Adler, J. Hansen-Møller, E. Thuen, A. M. Gustavsson, and H. Steinshamn. 2014. Gastrointestinal metabolism of phytoestrogens in lactating dairy cows fed silages with different botanical composition. J. Dairy Sci. 97:7735-7750.

Petit, H. V., and N. Gagnon. 2009. Milk concentrations of the mammalian lignans enterolactone and enterodiol, milk production, and whole tract digestibility of dairy cows fed diets containing different concentrations of flaxseed meal. Anim. Feed Sci. Technol. 152:103-111.

Petit, H. V., N. Gagnon, P. S. Mir, R. Cao, and S. Cui. 2009. Milk concentration of the mammalian lignan enterolactone, milk production, milk fatty acid profile, and digestibility in dairy cows fed diets containing whole flaxseed or flaxseed meal. J. Dairy Res. $76: 257-264$.

Phillips, G. M., and T. J. Taylor. 1973. Theory and Application of Numerical Analysis. Academic Press, New York, NY.

Quigley, J. D.. J. J. Drewry, and K. R. Martin. 1998. Estimation of plasma volume in Holstein and Jersey calves. J. Dairy Sci. 81:1308-1312.

Rada, V., E. Vlkov, J. Nevoral, and I. Trojanov. 2006. Comparison of bacterial flora and enzymatic activity in faeces of infants and calves. FEMS Microbiol. Lett. 258:25-28.

Setchell, K. D. R., and H. Adlercreutz. 1988. Mammalian lignans and phyto-oestrogens recent studies on their formation, metabolism and biological role in health and disease. Pages 315-345 in Role of the Gut Flora in Toxicity and Cancer. I. Rowland, ed. Academic Press, London, UK.

Smith, H. W. 1965. The development of the flora of the alimentary tract in young animals. J. Pathol. Bacteriol. 90:495-513.

Uetake, K. 2013. Newborn calf welfare: A review focusing on mortality rates. Anim. Sci. J. 84:101-105. 